\title{
Exploring Environmental Colour Design in Urban Contexts
}

\author{
Galyna McLellan, Mirko Guaralda \\ Queensland University of Technology, Australia \\ School of Design, Creative Industries Faculty \\ galyna.mclellan@qut.edu.au | m.guaralda@qut.edu.au
}

\begin{abstract}
The increasing complexity of urban colour and growing recognition of its psychological effects prompts rethinking of the current conceptual and methodological approaches to environmental colour design. Contemporary designers are challenged to understand how evolving colour knowledge can be integrated with the fundamentals of colour design. This paper aims to elaborate on the concept of environmental colour composition (ECC) and outlines an alternative approach to colour design in urban environments. A better understanding of the dynamic relationships between the tangible and perceptual elements of an ECC can bring new meaning to the consideration of colour as an integral component of city design. The proposed concepts of environmental colour events and scenarios provide a foundation for both further theoretical inquiry and practical application of synthesised colour knowledge in the design of urban environments.
\end{abstract}

Keywords: environmental colour composition, environmental colour design, colour event, colour scenario

To cite this article:

McLellan, G. and Guaralda, M. (2018). Exploring Environmental Colour Design in Urban Contexts. The Journal of Public Space, 3(I), 93- 102, DOI: I0.5204/jps.v3iI.320

This article has been peer-reviewed and accepted for publication in The Journal of Public Space. Please see the Editorial Policies under the 'About' section of the journal website for further information.

This work is licensed under a Creative Commons Attribution - Non Commercial 4.0 International License https://creativecommons.org/licenses/by-nc/4.0/ 
'What is the colour of your favourite public place?' Surprisingly, this simple question often causes confusion among many interviewees. Indeed, the complexity and ambiguity of visual information presented to viewers in a contemporary urban space make it difficult to determine what the prevailing spatial colour is. However, designers should not overlook the significant role of colour combinations in visual imagery and perceptual experiences in urban environments.

The perceptual aspects of colour were first theoretically explored by Goethe. In a treatise published in 1810, Goethe reflected on the interaction of various colours placed in proximity and suggested that 'if in this intermixture the ingredients are perfectly balanced that neither is to be distinctly recognised, the union again acquires a specific character, it appears as a quality by itself in which we no longer think of combination' (Goethe, 1810: 277). The value of colour totality or wholeness can be expressed in terms of harmony. Harmonious and pleasant colour compositions might elicit feelings of joy and appreciation of visual experiences. In reality, when people walk along the shopping malls and streets or rest in city squares, they may not consciously notice specific artefact colours, but rather feel an emotional response to the overall atmosphere. From our observations, the expressions 'this place makes me feel good' or 'it is quite a disturbing surrounding' often substitute as assessments of the colour combinations displayed. Gothe's colour theory has long been considered an intuitive, mostly poetic account. However, the relevance of his hypothesis to contemporary findings in the field of environmental colour psychology is undeniable. As Itten (1970: 2I) states, 'expressive colour effects - what Goethe called the ethic-aesthetic values of colour - likewise fall within the psychologist's province'. Numerous studies conducted over the last three decades have specifically extended our understanding of the effects of colour on the psychological stances of the urban dweller. For instance, Mahnke (1998) suggests that patterns and combinations of colours in the urban environment trigger emotional responses on both conscious and unconscious levels. Obscure visual patterns and disharmonious colour schemes can cause visual disturbances, disorientation, stress or low mood. In contrast, harmonious and contextually tailored colour areas stimulate positive emotions, eliminate visual disorder and enhance social interaction (Mahnke, 1998; Porter \& Mikellides, 2009). Given that colour is a sensory stimulus, it may also contribute to psychological under- or overstimulation of some individuals. Whereas overstimulating environment features exposed saturated colours, strong contrasts and flickering illumination. An understimulating setting is usually monochromatic and lacks contrast and visual accents. While sensory overstimulation may increase anxiety and depression, understimulation causes deprivation or excessive emotional responses (Franz, 2006; Mahnke, 2004). According to Day (2004), the relationships between urban forms, spaces and colour can be life sapping or life-filling.

Over the last two decades, the use of innovative building materials and advanced lighting technologies has altered the complexity of colour patterns and visual experiences available to city dwellers. Porter and Mikellides (2009: I) suggest that 'facades can now change colour depending upon the perceptual point of view, they can thermochromatically colour-react to daytime and seasonal temperature shift, be chromatically animated by sensors, by light-projection systems or by plasma screens'. Lenclos (2009: 86) also states 'architectural colour, now expressed in materials and illumination rather than paint, is creating a new chromatic dialectic between form, space, structure and light'.

94 | The Journal of Public Space, 3(I), 20I8 | ISSN 2206-9658

City Space Architecture / Queensland University of Technology / UN-Habitat 
The increasing complexity of urban colour and the recognition of its psychological effects has prompted rethinking of the conceptual and methodological approaches to environmental colour design. The challenge for contemporary designers is understanding how evolving colour knowledge can be integrated with the fundamentals of colour design and how colour can be used to balance sensory stimulation and create desirable polychromatic experiences in urban contexts.

Research in environmental colour psychology provides valuable information that can potentially guide design rationales but is not directly applicable to design methods (Anter \& Billger, 2008). Sharpe (198I) stated that the extensive data on colour psychology must to be organised and explained before a useful design methodology can be formulated. However, few scholars pursue systematic studies in this field from a designer's perspective.

Some leading architects search for their own methods to approach polychromatic environmental design in a holistic way. For example, McLachlan (20I4) provided an insightful account of the eight architectural practices known for their distinguished use of colour. Among others, she endorsed Sauerbruch and Hutton for their phenomenological approach to architectural colour and design of dynamic colour experiences. Similarly, Steven Hall received praise for his experimentation with the transformative nature of colour and light. Mark Major (2009: 15 I-158) reviewed work that inspired expression of colour through light, as exemplified in the Zollverein Kokerei industrial complex in Gelsenkirghen, Germany and the Burj Al Arab tower in Dubai. He claims that 'the seemingly infinite flexibility provided by the new generation of tools ... allow[s] lighting designers, architects and artists to approach the use of colour in architecture in a progressive manner' (Major, 2009: 154). Prominent lighting artist Yann Kersale (2009) describes his experimental installations on landmark buildings (designed by Jean Nouvel, Helmut Jahn and Patric Bochain) as articulating his vision of a 'luminous, nocturnal architecture of colour and light' (Porter \& Mikellides, 2009). Despite individual contributions, a comprehensive colour design framework that can be utilised by mainstream architecture and urban design remains undeveloped.

The methods for documenting and presenting colour design projects also require designers' attention. Conventional architectural palettes and city colour plans are generally created under controlled lighting conditions and documented in the form of two-dimensional swatches that represent materials or pigments. In real settings, the harmonious colour combinations selected by a designer can be affected by the interplay between the visual elements presented and intervention by large-scale digital advertising. Neither architectural palettes nor city colour plans can adequately reflect dynamic changes in environmental conditions or describe the likely psychological experiences in actual urban spaces.

These concerns have evolved into the concept of environmental colour composition (ECC), a holistic representation of an urban colour scheme. An ECC was initially defined by Ronchi (2002) as a synthesis of the colour of all visual elements within an urban setting, including natural elements, colours of built forms and urban elements as well as spatial and human activity patterns. This perspective aims to broaden the boundaries of an architectural palette and expand the traditional dimensions of colour in city design. However, its conceptual framework requires further clarification (specifically of the components of a contextual ECC) to provide the foundation for a shift in the colour design paradigm. 
In line with this need, we argue that a thorough interpretation the ECC phenomenon is a first step in developing a holistic approach to environmental colour design (ECD). A better understanding of the dynamic relationships between the tangible and perceptual elements of an ECC can bring additional meaning to the consideration of colour as an integral component of city design. Therefore, the purpose of this paper is $(I)$ to elaborate on the conceptual definition of the ECC in the context of public urban areas and (2) to outline an alternative approach to ECD that is underpinned by the synthesis of traditional colour design methods and psychological perspectives.

\section{Environmental Colour Composition in Contemporary Urban Contexts}

In urban contexts, the concept of colour has traditionally been considered in terms of architectural colour palettes and city colour plans. The selection of colour in architecture is essentially concerned with the aesthetic quality of a building. Practically, an architectural palette may be used to highlight or camouflage an entire built form, to enhance tectonic facades or details and to express the personal style of a designer or brand. Instead, city colour plans have usually considered the role of an individual building within a public area and have pursued visual compatibility of architectural colours within that urban area. Several widely promoted approaches to polychromic urban architecture advocate the use of colour with reference to both location and historical and cultural traditions. For example, Giovanni Brino (2009) developed methods of colour restoration in historical city centres that were adopted by 50 Italian cities. The colour plan of Turin in Italy aimed to restore the colour of facades on a citywide scale with reference to a historical prototype that originated in the Baroque period and was recovered at the beginning of the nineteenth century. Significant aspects of the colour plan developed by the Conseil des Ediles were manifested in the uniformity of architectural colour according to a coordinated system.

The focal point of Lenclos's Geography of Colour was the use of colour palettes associated with a local identity and sense of place. In a detailed account of colour meanings in urban environments, Lenclos (2009: 84-87) argued that colour is not an additional decoration, but rather a constituent of light that is influenced by climatic conditions, latitude, seasonal cycles and surface textures. His earlier work (1989) is associated with critical regionalism, but he has since built upon the transformative nature of contemporary colour that is sensitive to cultural, social, political and technological effects. From this new perspective, he stated: 'I am convinced that we are now experiencing a very important period in which architectural colour, now expressed in materials and illumination rather than paint is creating a new chromatic dialectic between form, space, structure and light' (2009: 86). Spillmann's original palette for Kirchsteigfeld in Potsdam was inspired by the concept of 'unity in diversity' and aimed to consolidate urban relationships while providing 'a colourintense discrimination between public, semi-private and private spaces' (Spillmann, 2009: 36). The novelty of Spillmann's methodology has been underpinned by the integration of functional, environmental and social aspects of colour design in the contemporary built environment. He argued that 'the most harmonious colour combination will lose its harmony if it does not correspond with specific human needs and activities, if it does not fit with the given surroundings, or if it does not sensibly interpret the building structure' (cited in Schindler, 2004: 64).

The conceptual frameworks developed by Bruno, Lenclos and Spillmann provided foundations for further exploration of colour phenomena in contemporary cities. For 
instance, Ronchi (2002) introduced another view of ECC that reflected the complexity and dynamics of colour images in urban settings. According to Ronchi (2002), an ECC includes the colours of natural elements, built forms and urban elements. Perception of ECC is influenced by pattern of spatial arrangements and human activities. A literature review revealed fragmented theoretical considerations that can be combined to enhance Ronchi's (2002) definitions. Recently, Zennaro (2017) defined the factors that influence perception of environmental colour as the size and functional use of buildings and the dimensions of, and relationships between, urban elements such as streets and public squares. Further, he emphasised the importance of geographical location, history and cultural traditions. Based on this combined knowledge, the main elements of any ECC can be classified as shown in Figure I.

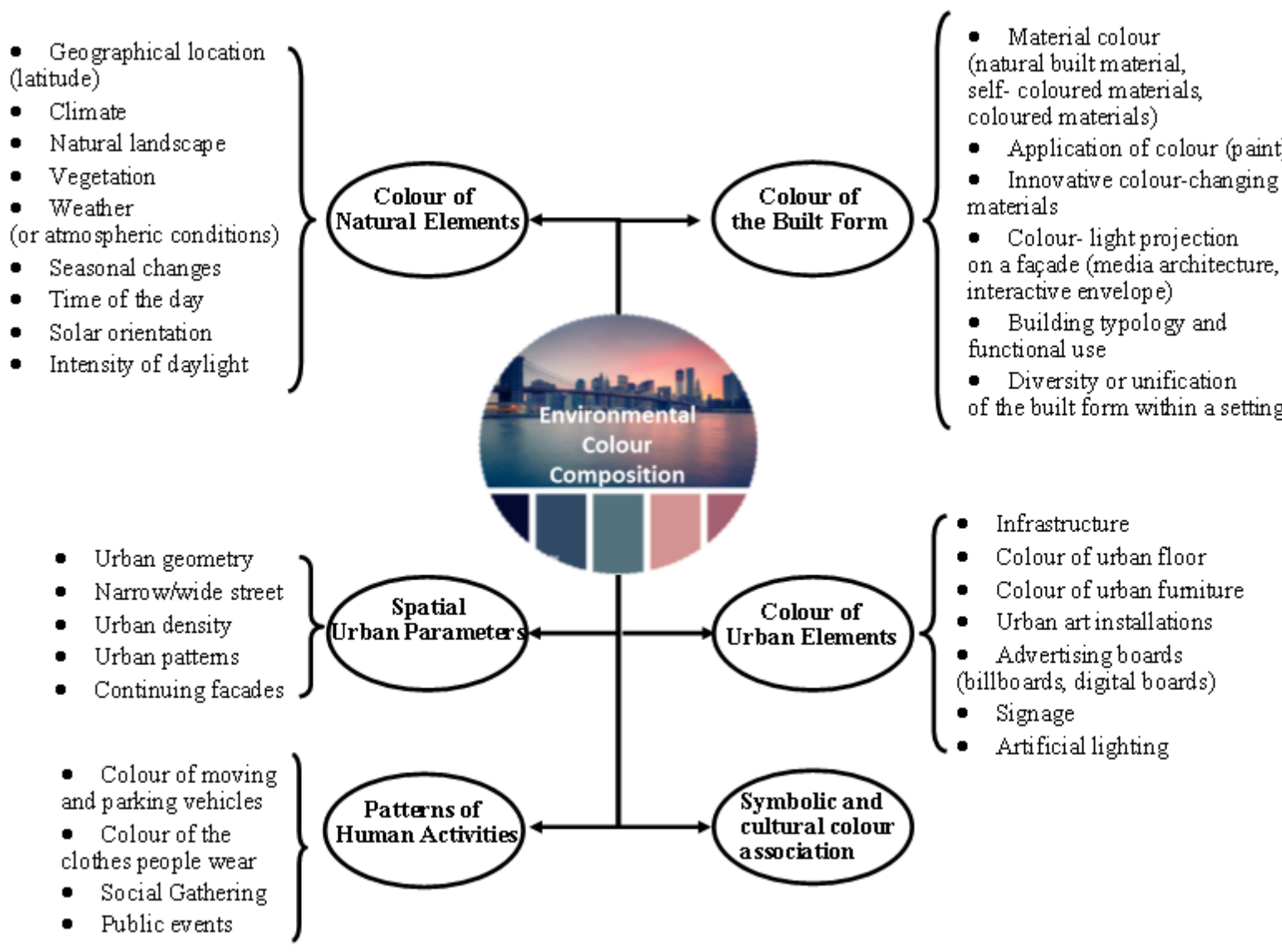

Fig. I. Core Elements of Environmental Colour.

The complexities and combinations of core ECC elements differ substantially between urban settings and depend on multiple factors. For example, certain colours presented in urban environments can be understood as measurable physical properties. Others correlate with visual experiences and are defined through the viewer's perception. Thus, ECC has both tangible and intangible properties.

In a practical sense, the classification described here can be used to assess the visual elements of an ECC within diverse historical and cultural conditions. Indeed, the original ECCs of Turin, Italy in the nineteenth century would be more unified in terms of colour 
compared to those in the city of Brisbane, Australia. The rapidly increasing complexity of ECCs in contemporary cities could be mainly attributed to changes in the density and volume of built forms; intervention of large-scale digital billboards and urban art installations; use of innovative colour-changing and highly reflective materials; development of new lighting technologies and the introduction of media facades. In the Brisbane context, the media facades and laser light projections on buildings remain limited and circumstantial. In contrast, giant advertising boards frequently appear on the ground, midsections of high-rise buildings and even on the rooves of heritage buildings. In some cases, the dimensions of such boards are almost equal to or bigger than the host building itself (see Figure 2). The saturated and flickering images of a digital billboard may overpower architectural colour, create colour dissonance and affect the visual experiences of both pedestrians and vehicle commuters. When installed on historical buildings, these boards may compromise the historical and cultural value of the public space or produce undesirable symbolic associations.
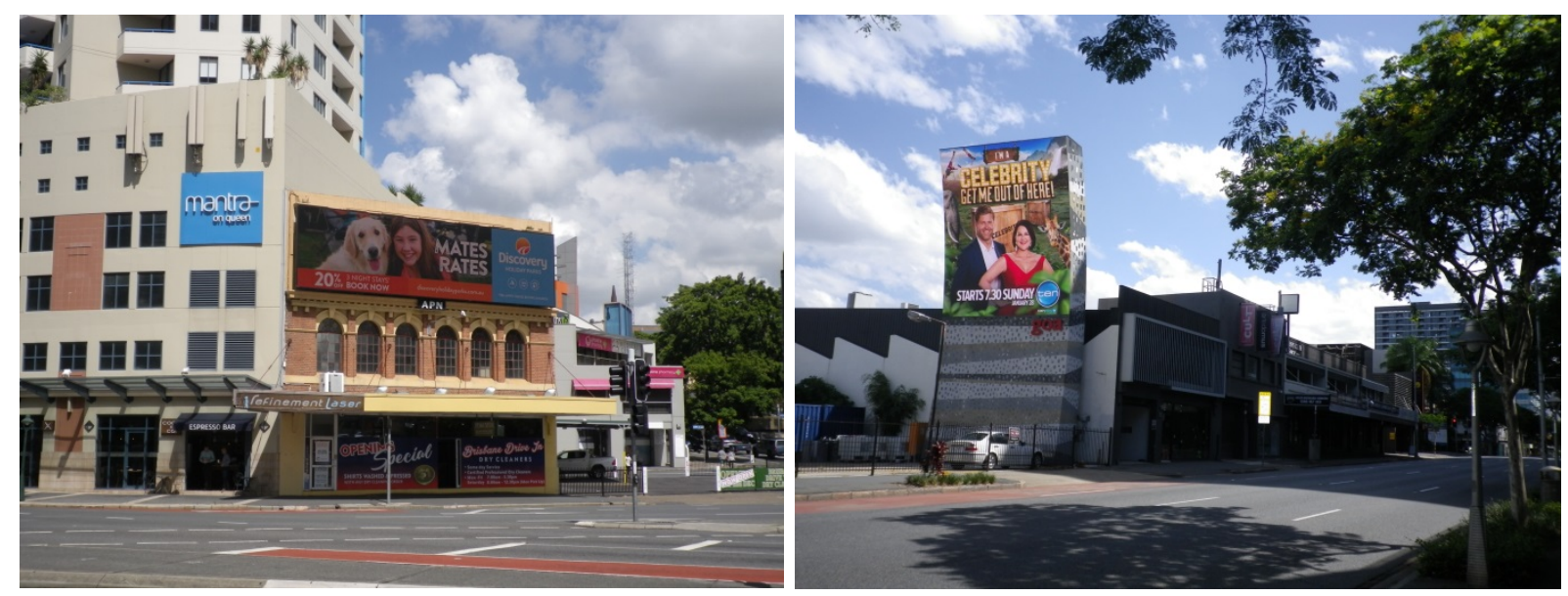

Fig. 2. Large digital board installations in Brisbane. These are found (a) on the roof of a historical building and (b) ground-standing digital board attached to a building used as a background. Photographs are the authors' own.

Another notable tendency in the use of colour is the expression of branding colour on facades. This means that entire commercial buildings have been painted in a brand-related colour without consideration of the potential effects of this approach on the perceived colour schemes (and thus, the appearance and aesthetics) of the surrounding area. A better understanding of the interrelated layers of colour in contemporary urban contexts may assist architects, urban designers and planners with surveying and analysing existing ECCs. This would allow development of a rationale for colour palette selection for singular infills or urban renewal proposals and for the approval of installations on existing buildings. Additionally, this knowledge may inform an alternative approach to ECD and suggest a more effective way of presenting the ECD product to clients, stakeholders and communities. 

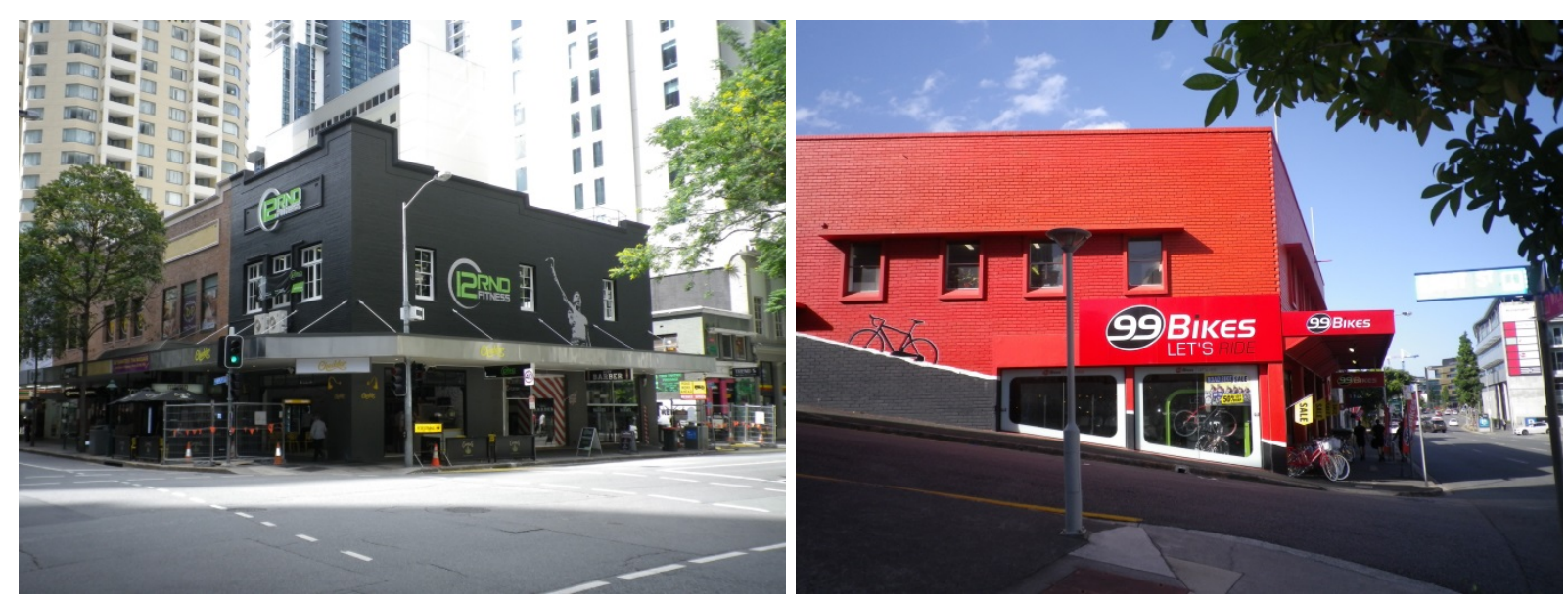

Fig. 3. Expression of brand-related colours on buildings in Brisbane. Photographs are the authors' own.

\section{Conceptualisation of Environmental Colour Events and Scenarios}

The environmental colour event (ECE) hypothesis originated from Ronchi's conception of ECC, but it celebrates the dynamic nature of colour in urban environments. This way of thinking was initially inspired by Cruz-Deiz's (2009: II) philosophical discourse, which claims that:

Colour reveals itself as a powerful means to stimulate the perception of reality. Our conception of reality today is not that of 12 th century man for whom life was a step towards eternity. On contrary, we believe in the ephemeral, with no past and no future, and where everything changes and is transformed in an instant. The perception of colour reveals such notions. It highlights space ambiguousness and ephemeral and unstable conditions, whilst underpinning myths and affections.

Later in this discourse, Cruz-Deiz (2009: 56) interprets colour as an ephemeral event that takes place in space and time. This concept is based on his personal reflections and intuitive exploration. Cruz-Deiz does not elaborate on the essential properties of a colour event; however, the universality of his philosophical assumption provides a foundation for inferring environmental colour as a dynamic and spatiotemporal event. Building upon the Ronchi's (2002) and Cruz-Deiz's (2009) concepts, the ECE can be related to the ECC of an urban space within a variable timeframe. Therefore, an ECE is characterised by both static and dynamic properties. The static properties are representative of the inherent colours of the built forms and urban elements. They are associated with the functional use, aesthetic value or symbolic meaning of colour. The dynamic properties reflect changing conditions influenced by natural and coloured artificial light, running images of digital billboards, interactive art installations and human activity.

Light and colour are inseparable factors in the process of environmental perception (Anter, 2000). During the day, the angle of natural light changes, which affects the appearance of perceived colours. Further, Tosca (2002) argues that contemporary cityscapes are significantly influenced by both natural light and artificial illumination, the latter of which makes it possible to visually modify the appearance of objects and space independent of viewing angles, distance and movement. Thus, Tosca (2002: 442) defines 
two distinct images: 'the cityscape of daylight and that of the artificial light'. For examples of this in Brisbane, see Figure 4.
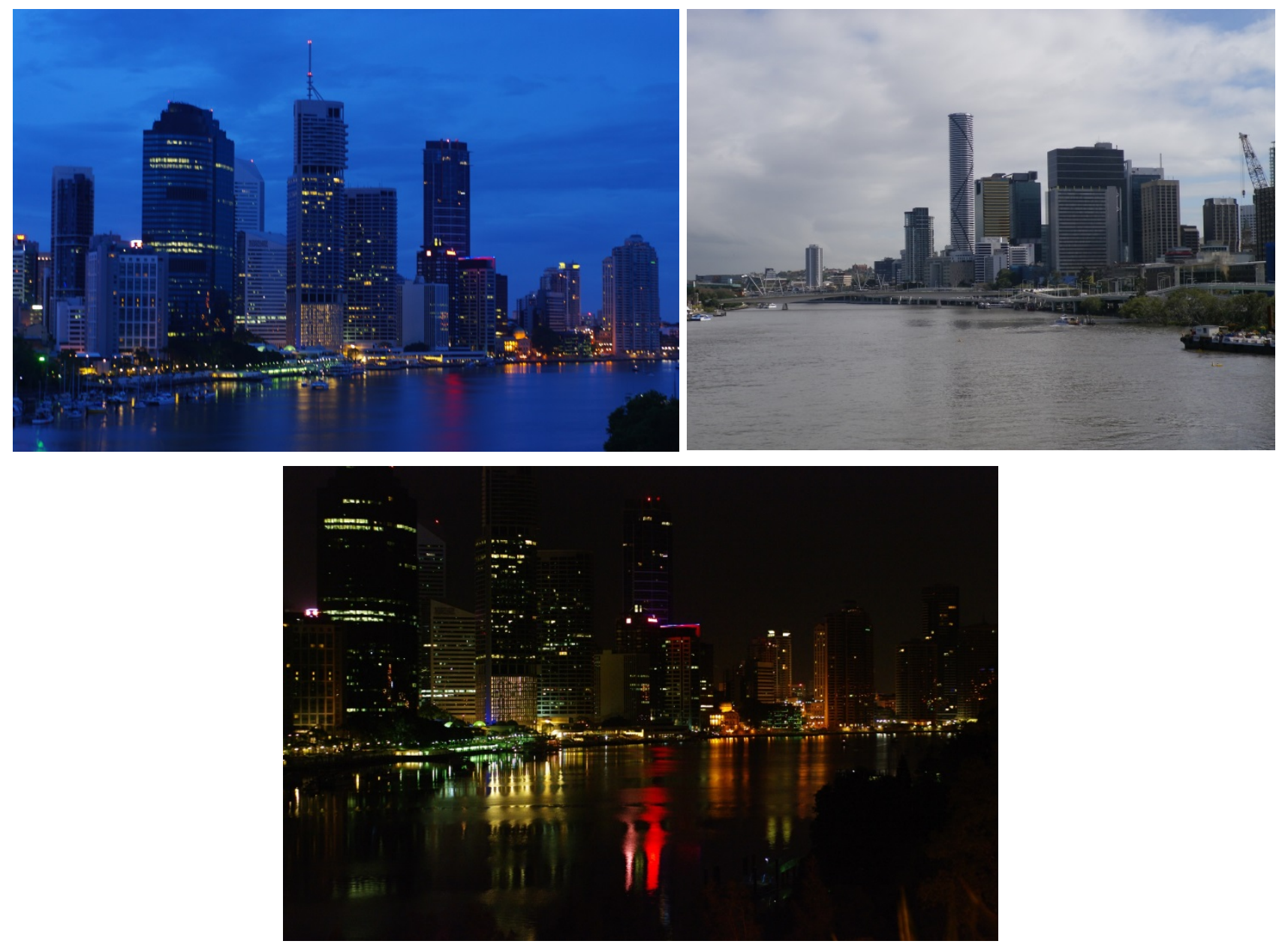

Figure 4. Brisbane city: morning and night. Photographs are the authors'.

Lenclos (2009: 86) draws a parallel with Tosca (2002) and suggests that:

Yet another phenomenon is commonly seen in today's cities across the world where buildings are no longer designed to function as an architectural event to be expressed during the light of day. Using a programmed choreography of coloured light, they can transform into a dynamic after-dark spectacle which can either complement or contrast with their daytime appearance. Well-known examples of this dual existence are found in Jean Nouvel's Agbar Tower in Barcelona which, after nightfall, assumes a new and vibrant persona.

Presumably, illumination as a design element of ECE allows linkage of day and night-time visual experiences. Dynamic lighting setups can be created to smooth the transition between sunlight and nocturnal ambience by balancing visual stimulation within changing conditions. Purpose-selected coloured lighting may emphasise the symbolic meaning of local colour and enhance the cultural identity of an urban area.

The idea of continuity in visual experiences relates to our original interpretation of environmental colour scenarios. Following the definition of ECE, an environmental colour 
scenario (ECS) is a coordinated set of recurring ECEs linked by a thread of identifiable colour leitmotifs. Hypothetically, a designed colour scenario contributes to harmonious and balanced relationships between the static and dynamic colours of an urban setting. Additionally, the variations of ECEs within a designed scenario enrich visual experiences. Inference of ECS as a holistic design approach is ontologically rooted in the "primary design' theory invented by Castelli. The theory shifts focus in colour design towards the non-material —or so-called 'soft'-aspects, which generally remain secondary in design rationales and are often underestimated by architects (Thackara, 1985: 28). These soft aspects include colour, light, microclimate, decoration and even odour and background sound. Castelli (cited in Mitchell, 1993) claims that his design approach intentionally eliminates forms and considers colour, light, texture and sound as means of design. He also emphasised the limitations of the traditional two-dimensional presentation of architectural designs. According to Castelli (cited in Mitchell, 1993: 88), two-dimensional architectural drawings 'tend to stress the objective properties of a product and neglect the subjective aspects, including sensual qualities'.

Mitchell (1993) positioned 'primary design' within the contextual design trend that is considered a catalyst for the user's perceived aesthetic experience. In keeping with contextual design traditions, an ECS is primarily concerned with experiences of colour and light in urban environments. This design approach aims to create a context in which an ECE will be perceived. However, a question that arises is whether the proposed concepts of ECS may inform applicable design methods.

The description of an ECD methodology is outside the scope of this paper. Rather, we hope to initiate debate on this important topic. Ronchi (2002) defines ECD as 'a holistic approach to the design of environmental colour composition on different spatial scales, which involves a parallel analysis of architectural, semiotic, illumination-related data as well as human-environment interaction'. This definition underlines the fundamental procedural differences between ECD and the more traditional application of colour in form design.

From our perspective, as a tangible element of an ECE, an environmental colour palette can be created using the fundamental principles of colour harmonies and contrasts.

Environmental colour and material palettes can be documented and matched to the NCS colour order system in a conventional way. The initial environmental colour palette can be merged with a lighting design to create desirable visual experiences bounded by an ECS. ECEs can only be understood through perception and emotions. Psychological responses to environmental colour are subjective and difficult to assess. However, an augmented reality simulation may allow prospective users to virtually experience a singular ECE or a whole ECS and then describe their emotions using appropriate psychometric charts. To achieve a realistic presentation, the augmented simulation should integrate measurable parameters and perceived characteristics of an ECS. To make this process more user-centred, the initial design objectives can be modified based on the users' responses. While the process described may sound complicated, it could be simplified by a thorough design application program. We believe that many practicing architects and urban designers would agree that there is a need for an application to merge theoretical and multidisciplinary colour knowledge in a meaningful way. In conclusion, a better understanding of the complexity and psychological effects of ECCs in contemporary urban settings can guide a more informed and user-responsive approach to ECD. The proposed concepts of ECE and ECS provide a foundation for further theoretical inquiry and the development of an applicable design methodology that could 
be used by practicing architects, urban designers and planners. The exploration of ECS in urban contexts reveals opportunities for a holistic approach to ECD based on an appreciation of both colour theories and designs for positive visual experiences.

\section{References}

Anter, K. (2000). What colour is the red house? Perceived colour of painted facades. Stockholm: Architecture, Royal Institute of Technology.

Anter, K. F., \& Billger, M. (2008). Colour research with Architectural Relevance: How Can Different Approaches Gain From Each other? Colour Research and Application, 35/2, 145 - 152.

Brino, G. (2009). Italian city colour plans (1978-2007). In T. Porter \& B. Mikellides (Eds.), Colour for architecture today (pp. 30-35). London, UK: Taylor \& Francis.

Cruz-Diez, C. (2009). Reflection on colour. Houston, Texas: Cruz-Diez Foundation.

Day, C. (2004). Place of the soul. Architecture and environmental design as a healing art. Oxford: Elsevier, Architectural Press.

Doherty, G. (2010). Urbanism of colour. Harvard: University Press.

Franz, G. (2006). Space, color, and perceived qualities of indoor environments. In M. Tolba, S. Soliman \& A. Abdel-Hadi (Eds.), Environment, health, and sustainable development-proceedings of the 19th International Association for People Environment Studies conference (IAPS 2006) (pp. I-8). Seattle, WA: Hogrefe \& Huber.

Goethe, J. W. (1970). Theory of colours. Cambridge: The MIT Press.

Itten, J. \& Birren, F. (1970). The elements of colour: A treatise on the colour system of Johannes Itten based on his book the art of colour. New York: Van Nostrand Reinhold.

Lenclos, J. P. (1989). The geography of colour. Tokyo: San'ei Shobo Publishing.

Lenclos, J. P. (2009a). The geography of colour. In T. Porter \& B. Mikellides (Eds.), Colour for architecture today (pp. 30-35). London, UK: Taylor \& Francis.

Lenclos, J. P. (2009b). The globalisation of colour. In T. Porter \& B. Mikellides (Eds.), Colour for architecture today (Pp. 84-87). London, UK: Taylor \& Francis.

Major, M. (2009). In T. Porter \& B. Mikellides (Eds.), Colour for architecture today (Pp. I5I- 158). London, UK: Taylor \& Francis.

Mankhe, F. (1996). Colour, environment and human response. New York: Van Nostrand Reinhold.

McLachlan, F. (20I2). Architectural colour in the professional palette. London and New York: Routledge.

Mitchell, C. T. (1993). Redefining designing. From form to experience. New York: Van Nostrand Reinhold.

Porter, T. \& Mikellides, B. (Eds.) (2009). Colour for architecture today. London, UK: Taylor \& Francis.

Ronchi, L. (2002). Light and colour in environmental design: Some annotated terms. Retrieved from http://www.fadu.uba.ar/sitios/sicyt/color/glossary.htm.

Sharpe, D. T. (198I). The Psychology of Colour and Design. Totowa, New Jersey: Littlefield, Adams and Co.

Schindler, V. M. (2004). Colour as vocation: Werner Spillmann's contribution to environmental colour design. Colour Research Application, 30, 53-65.

Spillmann, W. (2009). Unity in diversity at Kirchsteigfeld, Potsdam. In T. Porter \& B. Mikellides (Eds.), Colour for architecture today (pp. 36-38). London, UK: Taylor \& Francis.

Thackara, L. (1985). Designing without form. Design, 433, 28.

Tosca, T. F. (2002). Environmental colour design for the third millennium: An evolutionary standpoint. Colour Research and Application, 27(6), 44I-454.

Zennaro, P. (2017) Strategies in colour choice for architectural built environment. Journal of the International Colour Association, 19, 15-22. Retrieved from http://www.aiccolor.org/journal/v19/jaic_v19_02.pdf

102 | The Journal of Public Space, 3(I), 2018 | ISSN 2206-9658

City Space Architecture / Queensland University of Technology / UN-Habitat 